\title{
Interfacial design of $\mathrm{Cu}$-based composites prepared by powder metallurgy for heat sink applications
}

\author{
Th. Schubert ${ }^{\text {a } *}$, B. Trindade ${ }^{\mathrm{b}}$, T. Weißgärber ${ }^{\mathrm{a}}$, B. Kieback ${ }^{\mathrm{a}}$ \\ ${ }^{\text {a }}$ Fraunhofer-Institute for Manufacturing and Advanced Materials, Department of Powder Metallurgy and Composite Materials, \\ Winterbergstr. 28, D-01277 Dresden, Germany \\ ${ }^{\mathrm{b}}$ ICEMS, Mechanical Department of Coimbra University, Rua Luís Reis Santos, 3030-788 Coimbra, Portugal
}

Received 16 June 2006; received in revised form 5 December 2006; accepted 5 December 2006

\begin{abstract}
Thermal aspects are becoming increasingly important for the reliability of the electronic components due to the continuous progress of the electronic industries. Therefore, the effective thermal management is a key issue for packaging of high performance semiconductors. The ideal material working as heat sink and heat spreader should have a CTE of (4-8) $\times 10^{-6} \mathrm{~K}^{-1}$ and a high thermal conductivity. Metal matrix composites offer the possibility to tailor the properties of a metal by adding an appropriate reinforcement phase and to meet the demands in thermal management.

Copper/SiC and copper/diamond composites have been produced by powder metallurgy. The major challenge in development of $\mathrm{Cu} / \mathrm{SiC}$ is the control of the interfacial interactions. Silicon carbide is not stable in copper at the temperature needed for the fabrication of $\mathrm{Cu} / \mathrm{SiC}$. It is $\mathrm{known}$ that the bonding between diamond and copper is very weak in the $\mathrm{Cu}$ /diamond composite. Improvements in bonding strength and thermo-physical properties of the composites have been achieved by
\end{abstract}

- a vapour deposited molybdenum coating on $\mathrm{SiC}$ powders to control interface reactions,

- using atomized $\mathrm{Cu}(\mathrm{X})$ alloys with minor additions of carbide formers, e.g. $\mathrm{X}=\mathrm{Cr}, \mathrm{B}$, to improve the interfacial bonding in $\mathrm{Cu}$-diamond composites.

(C) 2007 Elsevier B.V. All rights reserved.

Keywords: Copper composites; Powder metallurgy; Thermal management; Heat sinks; Electronics

\section{Introduction}

Electronic packaging involves interconnecting, powering, protecting, and cooling of semiconductor circuits for use in a variety of microelectronic applications. For microelectronic circuits, the main type of failure is thermal fatigue, owing to the different thermal expansion coefficients of semiconductor chips and packaging materials. In addition, because the power density increases rapidly, the ability to dissipate heat becomes a very important factor. Therefore, materials having reduced coefficient of thermal expansion (CTE) mismatches with $\mathrm{Si}$, InP or GaAs in combination with a high thermal conductivity are required for heat sinks and heat spreaders. Comprehensive reviews of this field are given by Zweben [1] and German et al. [2].

\footnotetext{
* Corresponding author. Tel.: +49 3512537 346; fax: +49 3512537399

E-mail address: Thomas.Schubert@ifam-dd.fraunhofer.de (Th. Schubert).
}

Copper is one of the most important materials for thermal and electronic applications. It has higher electrical and thermal conductivities and a lower CTE than aluminum. Unfortunately, the thermal expansion of copper is about four times higher than that of the semiconductor silicon. SiC combines a thermal conductivity of about $200-300 \mathrm{~W} / \mathrm{mK}$ with a CTE of $4.5 \times 10^{-6} \mathrm{~K}^{-1}$, and offer a good availability, low price and possible machinability. In addition, diamond has exceptional thermal properties along with a low CTE of about $1.0 \times 10^{-6} \mathrm{~K}^{-1}$. The thermal conductivity of synthetic diamonds of Ib type can be estimated in the range of $1500-2000 \mathrm{~W} / \mathrm{mK}$. Therefore, the use of $\mathrm{SiC}$ or diamonds particles as reinforcements in copper based composites is considered very attractive to meet the increasing demands for high performance heat sink materials and packages.

When $\mathrm{SiC}$ or diamond particles are embedded in a copper matrix, the interface plays a crucial role in determining the thermal conductivity, the CTE and also the mechanical properties of 
the composite. An ideal interface should provide good adhesion and minimum thermal boundary resistance.

A silicon carbide reinforced copper composite is the aim of several investigations [3-5]. Unfortunately, silicon carbide is not stable in contact with copper at elevated temperatures. Silicon is partially dissolved in copper forming a copper(silicon) solid solution and pure carbon remains at the $\mathrm{Cu} / \mathrm{SiC}$ interface. Dissolved silicon reduces dramatically the thermal and electrical conductivities of $\mathrm{Cu} / \mathrm{SiC}$ composites. Therefore, diffusion barriers are necessary to prevent the detrimental interfacial reaction between copper and $\mathrm{SiC}$.

Pure liquid copper does not wet diamond and diamond/ $\mathrm{Cu}$ composites made by powder metallurgy have been shown to feature weak interfacial bonding; debonding occurred upon thermal cycling [6]. It is well known that alloying of copper with a strong carbide forming element promotes wetting and bonding of diamond. Even in case of solid phase bonding (e.g. hot pressing) high bonding strength was observed for copper alloys with minor additions of $\mathrm{Ti}, \mathrm{Cr}, \mathrm{B}$ or $\mathrm{Zr}[7,8]$. The influence of the interface formation on the thermal conductivity of these composite is not yet fully understood. Electrons dominate heat conduction in copper, whereas phonons dominate that in diamond. Hence, for the heat conductivity of the metal matrix composite (MMC) the energy transfer must occur between electrons and phonons. It is assumed, that a very thin interface layer of metallic ceramics can aid the necessary electron-phonon coupling.

In order to solve the interface problems between copper and the selected reinforcements, two approaches were investigated. Firstly, the application of a barrier coating onto $\mathrm{SiC}$ was used to control the chemical reaction of $\mathrm{Cu}$ and $\mathrm{SiC}$. In this study the effectiveness of a vapour deposited molybdenum layer was investigated. A second way is the use of different carbide formers added as alloying elements to the copper matrix in case of the diamond reinforcement. The critical issue is to control the process parametres such that the carbide layer is not growing too strongly in order to maintain a maximum thermal interface conductance. The thermo-physical properties will be displayed and discussed as a function of the reinforcements as well as the alloying element used for composite preparation. The differences between coated and uncoated powders will be discussed.

\section{Experimental}

Several pre-alloyed $\mathrm{Cu}(\mathrm{X})$ powders $(\mathrm{X}=\mathrm{B}, \mathrm{Cr}, \mathrm{Al}, \mathrm{Ti}, \mathrm{Zr}$ ) prepared by gas atomization were used to investigate the effect of adding alloying elements to the $\mathrm{Cu}$ matrix. The mean particle size $\left(d_{50}\right)$ of these powders is in the range of $10-15 \mu \mathrm{m}$. The pure reference copper used was a copper powder produced by wet chemical precipitation with $d_{50}$ of $6 \mu \mathrm{m}$ and a purity $>99.9 \%$.

The used particle reinforcements are synthetic MBD4 diamonds with a designated particle diameter of 125-100 $\mu \mathrm{m}$ (mesh 120/140) and PVD pre-coated SiC/F240-green (30-70 $\mu \mathrm{m})$ or $\mathrm{SiC} / \mathrm{F} 80$-green $(150-210 \mu \mathrm{m})$ with molybdenum. The coating by sputtering was performed at the Coimbra University, Portugal. During the deposition the powders were continually moved by vibration and translation motions in order to obtain homogeneous coatings. A coating thickness of about $180 \mathrm{~nm}$ can be
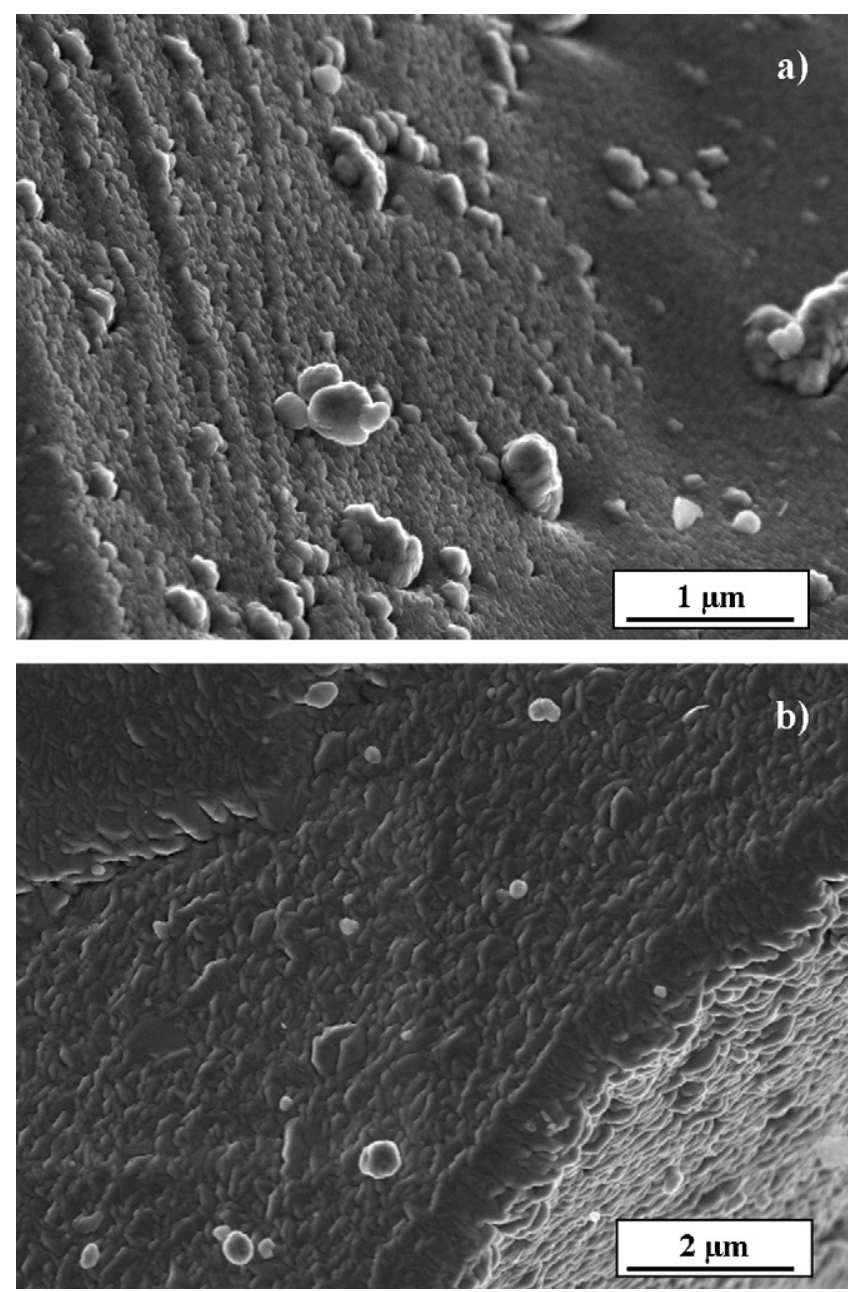

Fig. 1. SEM images of the Mo-coating layers on SiC powder particles with different magnifications: (a) $20,000 \times$; (b) $10,000 \times$.

estimated from density measurements using pycnometry. The inspection of the surface of the powders was performed by scanning electron microscopy (SEM) using a DSM 982 GEMINI equipment of ZEISS. The coated SiC powder reveals dense, homogeneous and well adherent molybdenum coatings on the SiC powder particles (Fig. 1).

Subsequently, the copper powders were mixed with the ceramic or diamond particles to prepare composites with about 40 vol.\% reinforcement. These composites were fabricated by hot pressing. In order to influence the hot pressing time via heating rate a hot press with indirect resistance heating (type HPW 315/400, manufactured by FCT Systeme GmbH, Germany) or a sintering press with a direct resistance heating for very fast heating (type DSP, developed by Dr. Fritsch GmbH, Germany) were used. The rapid sintering technique is especially promising for a cost efficient manufacturing of the composites.

The bulk density of the composites was measured by using a method based on Archimedes' law and compared with the theoretical density. The measurement of the coefficients of thermal expansion (CTE) was performed in a Netzsch dilatometer under the following conditions: temperature range $25-300^{\circ} \mathrm{C}$; heating rate $5 \mathrm{~K} / \mathrm{min}$; argon atmosphere. The linear CTE was measured 
in accordance with the equation:

$\alpha=\frac{1}{\Delta T} \varepsilon=\frac{1}{l_{0}} \frac{\Delta l}{\Delta T}$

where $\alpha$ is the coefficient of thermal expansion, $\Delta T=T-T_{0}$ the temperature interval $\left(T_{0}=293 \mathrm{~K}\right), \varepsilon=\Delta l / l_{0}$ the relative length change, and $\Delta l$ is the expansion for $\Delta T, \Delta l=l-l_{0}$. The length of the sample before testing is $l_{0}$. The thermal conductivity was measured by Xenon pyrometry with the Nanoflash of the company Netzsch, Germany. Fracture surfaces of the composite samples have been analysed by SEM.

\section{Results and discussion}

\section{1. $\mathrm{Cu} / \mathrm{SiC}$ composites}

Fig. 2 shows the typical microstructure of a $\mathrm{Cu}-40 \% \mathrm{SiC}^{\mathrm{Mo}}$ composite $\left(\mathrm{SiC}^{\mathrm{Mo}}-\mathrm{Mo}\right.$-coated $\mathrm{SiC}$ ) with the relatively homogeneous distribution of the $\mathrm{SiC}$ particles. In addition, small interfacial layers of molybdenum can be revealed at higher magnification. The hot pressing was performed at $980^{\circ} \mathrm{C}$ for $1 \mathrm{~h}$ using a hot press of type HPW (indirectly heated).

The results regarding the thermo-physical properties of the manufactured 40 vol.\% SiC reinforced $\mathrm{Cu}$ composites by using uncoated and pre-coated $\mathrm{SiC}$ particles are presented in Table 1.

The thermal conductivity of $\mathrm{Cu} / \mathrm{SiC}$ made using $\mathrm{SiC}$ without a protective barrier coating is very low and the corresponding CTE was only reduced to about $14 \times 10^{-6} \mathrm{~K}^{-1}$ compared to pure $\mathrm{Cu}$.

As stated before, $\mathrm{SiC}$ decomposes to $\mathrm{Si}$ and $\mathrm{C}$ in contact with copper at elevated temperatures. Si should be dissolved into $\mathrm{Cu}$ with a simultaneous decrease of the thermal conductivity of the matrix. The $\mathrm{C}$ for $\mathrm{Cu}$ affinity and the $\mathrm{C}$ solubility in $\mathrm{Cu}$ are negligible. Therefore, the remaining carbon can prevent a sufficient interfacial bonding which is also necessary for CTE reduction. The comparison of these values supports the use of a molybdenum coating onto the $\mathrm{SiC}$ particles to prevent the detrimental chemical reaction of $\mathrm{Cu}$ with $\mathrm{SiC}$ at the temperature $\left(980^{\circ} \mathrm{C}\right)$ used for $\mathrm{Cu} / \mathrm{SiC}$ fabrication. Mo and $\mathrm{Cu}$ are mutually insoluble and can form intimate composites best-known as thermal management material. Otherwise, the formation of carbides and silicides is well established as reaction products between Mo and $\mathrm{SiC}$ at elevated temperatures [9]. The release of free $\mathrm{Si}$ or $\mathrm{C}$ is not expected for the $\mathrm{Mo} / \mathrm{SiC}$ system.

Fig. 3 presents the thermal expansion behaviour of $\mathrm{Cu}-40 \% \mathrm{SiC}^{\mathrm{Mo}}$ composite after some thermal cycles between room temperature and $300^{\circ} \mathrm{C}$. The CTE values were only slightly increased indicating a relatively good interfacial bonding between the reinforcement and the copper matrix.
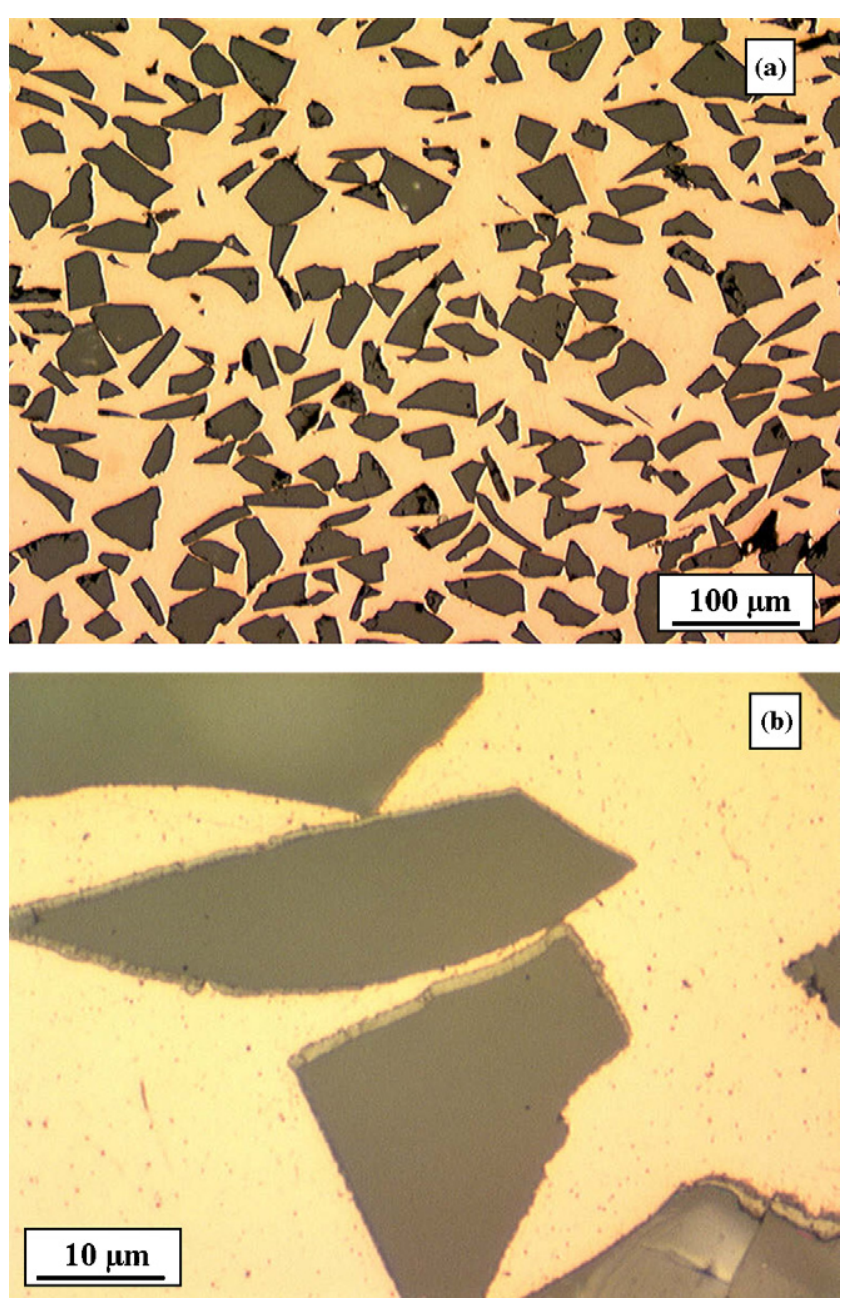

Fig. 2. Optical micrographs of the cross section of a hot-pressed $\mathrm{Cu}-40 \% \mathrm{SiC}^{\mathrm{Mo}}$ composite showing a homogeneus distribution of the $\mathrm{SiC}$ particles (a) and the Mo coating layers on the $\mathrm{SiC}(\mathrm{b})$.

\subsection{Cu/diamond composites}

The results regarding the thermo-physical and mechanical properties of the fabricated 42 vol. $\%$ diamond reinforced copper composites by using $\mathrm{Cu}$ based powders alloyed with different elements are presented in Fig. 4.

These results show that the alloying of the copper matrix with carbide-forming elements has a positive effect on the thermal properties of the $\mathrm{Cu}(\mathrm{X})$-diamond composites compared to pure copper matrix. However, the measured values also suppose a strong influence of the type of the alloying elements on the thermal properties of the composites. The carbide formers chromium and boron appear to be the best candidates for diamond containing copper composites. These elements have a

Table 1

Comparison of the thermo-physical properties of different $\mathrm{Cu} / \mathrm{SiC}$ composites

\begin{tabular}{|c|c|c|c|c|}
\hline Material & Thermal diffusivity $\left(\mathrm{mm}^{2} / \mathrm{s}\right)$ & Specific heat $(\mathrm{J} / \mathrm{g} \mathrm{K})$ & Thermal conductivity at $R T(\mathrm{~W} / \mathrm{m} \mathrm{K})$ & $\operatorname{CTE}\left(30-100^{\circ} \mathrm{C}\right)\left(10^{-6} \mathrm{~K}^{-1}\right)$ \\
\hline $\mathrm{Cu} / \mathrm{SiC}(\mathrm{F} 240)$ & 72 & 0.468 & 222 & 14.5 \\
\hline $\mathrm{Cu} / \mathrm{SiC}^{\mathrm{Mo}}(\mathrm{F} 240)$ & 93 & 0.467 & 288 & 10.6 \\
\hline $\mathrm{Cu} / \mathrm{SiC}^{\mathrm{Mo}}(\mathrm{F} 80)$ & 102 & 0.466 & 306 & 11.2 \\
\hline
\end{tabular}




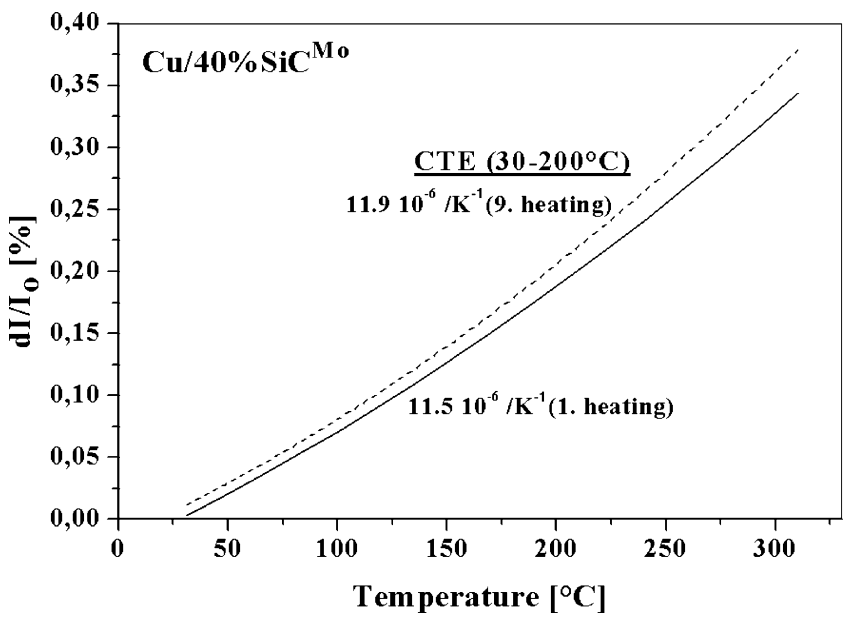

Fig. 3. Comparison of the thermal expansion behaviour of the $\mathrm{Cu}-\mathrm{SiC}{ }^{\mathrm{Mo}}$ composite during the first and the ninth heating to $300^{\circ} \mathrm{C}$.

low substitutional or interstitial solubility, respectively, in copper at processing temperature and a medium heat of formation of the carbide compared to the stronger carbide formers $\mathrm{Al}$, $\mathrm{Ti}, \mathrm{Zr}$. The achieved thermal conductivity could be doubled by using boron or chromium as alloying element. The corresponding CTE (30-200 ${ }^{\circ} \mathrm{C}$ ) was reduced to about $11 \times 10^{-6} \mathrm{~K}^{-1}$ by an improved interfacial bonding between the copper matrix and the diamond particles.

The thickness of an intermediate reaction layer can be estimated with about $350 \mathrm{~nm}$ assuming, that the used alloying content was completely transformed to the metal carbide at the surface of spherical diamond particles with a diameter of $120 \mu \mathrm{m}$. Fig. 5 shows the fracture surface of the hot pressed $\mathrm{CuCr}$ /diamond composite. The SEM image in the backscattered electron (BSE) mode (Fig. 5a) shows diamond surfaces with only few adhered residues of the copper matrix. But, the corresponding counterparts of the copper matrix and the diamond surfaces in the secondary electron (SE) mode (Fig. 5b) reveal spotted structures. These altered interfacial microstructures suggest that the bonding of copper onto the diamond occurs almost

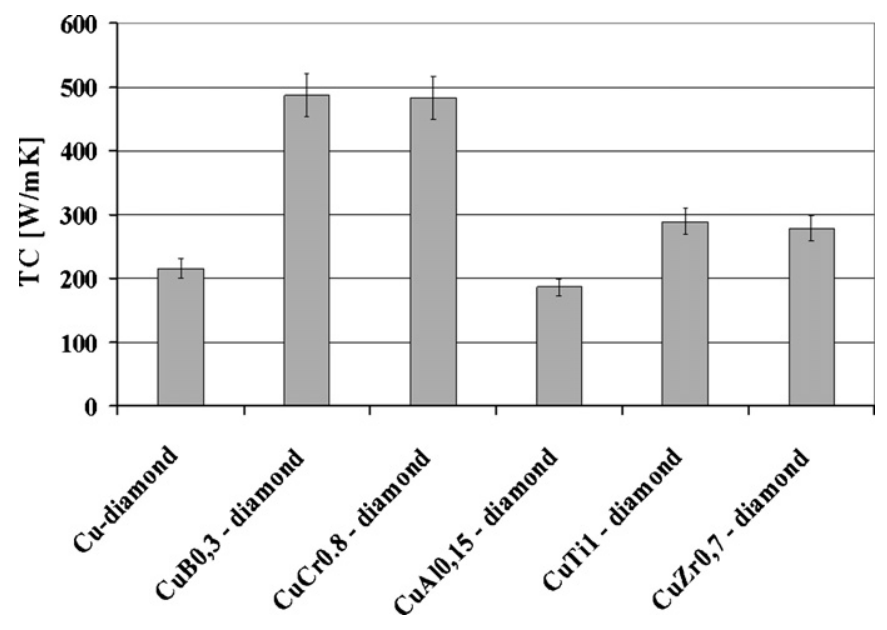

Fig. 4. Comparison of the thermal conductivities of different $\mathrm{Cu}(\mathrm{X}) / 42 \%$ diamond composites with $\mathrm{X}=\mathrm{B}, \mathrm{Cr}, \mathrm{Al}, \mathrm{Ti}, \mathrm{Zr}$ contents in wt\%.
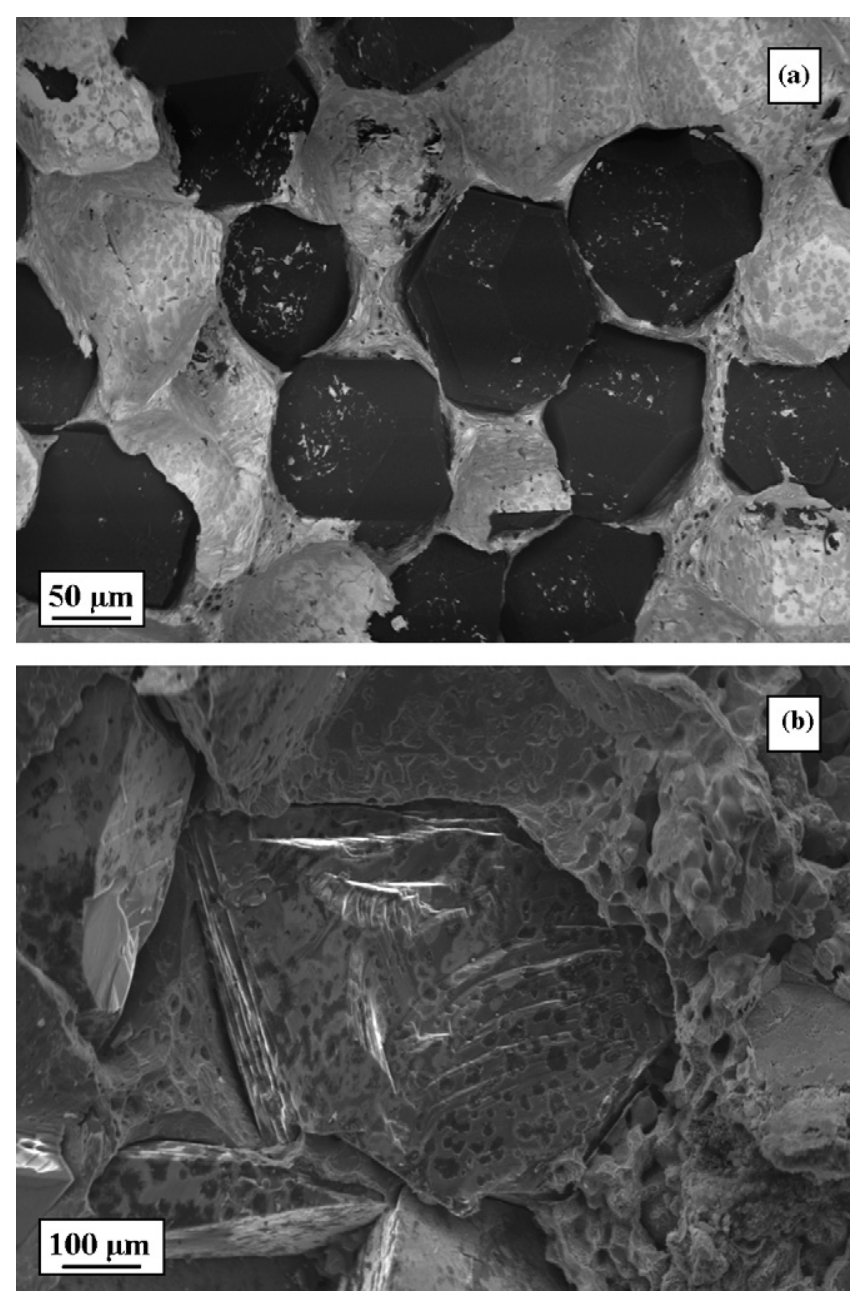

Fig. 5. SEM images of the fracture surface of a hot-pressed $\mathrm{CuCr} 0.8 / 42 \%$ diamond composite using the BSE signal (a) and the SE signal (b).

uniformly across the entire diamond surface by a chromium carbide formation. It may be assumed that the nucleation of $\mathrm{Cr}_{3} \mathrm{C}_{2}$ occurs preferentially at surface defects of the diamond crystals, where carbon may more easily be liberated to engage in carbide formation. The spotted appearance can be caused by local differences of the atomic number of the reaction product in case of BSE mode and topological effects in SE mode.

Within the first consolidation trials the same processing parameters were applied for the different powder mixtures. The hot pressing was performed at $950^{\circ} \mathrm{C}$ for $1 \mathrm{~h}$. Further improvement of the thermal conductivity of the diamond composites can be achieved by optimisation of the relevant processing parameters. This includes the volume content of the used carbide former and the hot pressing conditions (temperature, time). To demonstrate this potential for improvements of $\mathrm{CuCr} /$ diamond composites, the heating and cooling rates and the pressing time were varied by using indirectly and directly heated hot presses. The obtained values are compared to the theoretical predictions using the model of Hasselmann and Johnson [10] (Fig. 6). The calculations were made under the assumption of $42 \mathrm{vol} . \%$ of spherical diamond particles with diameter $d=120 \mu \mathrm{m}$ and the thermal conductivities of 1500 and $400 \mathrm{~W} / \mathrm{mK}$ for diamond and 
Table 2

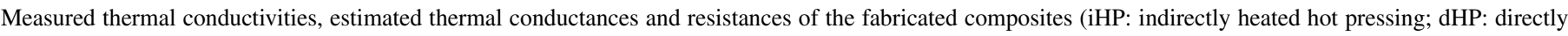
heated hot pressing)

\begin{tabular}{|c|c|c|c|c|c|}
\hline Material & $\begin{array}{l}\text { Hot pressing } \\
\text { time }(\min )\end{array}$ & $\begin{array}{l}\text { Thermal diffusivity } \\
\left(\mathrm{mm}^{2} / \mathrm{s}\right)\end{array}$ & $\begin{array}{l}\text { TC at } R T \\
(\mathrm{~W} / \mathrm{m} \mathrm{K})\end{array}$ & $\begin{array}{l}\text { Thermal conductance } \\
\left(\mathrm{MW} / \mathrm{m}^{2} \mathrm{~K}\right)\end{array}$ & $\begin{array}{l}\text { Thermal contact } \\
\text { resistance }\left(\mathrm{m}^{2} \mathrm{~K} / \mathrm{W}\right)\end{array}$ \\
\hline $\mathrm{Cu} /$ diamond & 60/iHP & 80 & 215 & 0.5 & $2 \times 10^{-6}$ \\
\hline \multirow[t]{5}{*}{$\mathrm{CuCr} /$ diamond } & 60/iHP & 175 & 482 & 17 & $6 \times 10^{-8}$ \\
\hline & 45/iHP & 192 & 515 & 23 & $4.5 \times 10^{-8}$ \\
\hline & 30/iHP & 183 & 483 & 17 & $6 \times 10^{-8}$ \\
\hline & 20/dHP & 213 & 590 & 47 & $2 \times 10^{-8}$ \\
\hline & 30/dHP & 221 & 639 & 94 & $1 \times 10^{-8}$ \\
\hline
\end{tabular}

the copper matrix, respectively. The estimated thermal conductance and contact resistance are summarised in Table 2.

In the pure copper/diamond composite the interfacial thermal conductance is less than $1 \times 10^{6} \mathrm{~W} / \mathrm{m}^{2} \mathrm{~K}$. This can be explained by no chemical affinity between copper and diamond, and therefore no interfacial bonding and no electron-phonon coupling for a optimum thermal transfer at the interface. The rapid sintering technique with holding times up to $30 \mathrm{~min}$ and heating/cooling rates of $100-150 \mathrm{~K} / \mathrm{min}$ results in the most promising thermal diffusivity and conductivity values compared to the conventional hot pressing with heating/cooling rates of about $10 \mathrm{~K} / \mathrm{min}$. In the case of a Cr-doped copper matrix, an enhancement of the conductance value by factor about 200 to about $9.4 \times 10^{7} \mathrm{~W} / \mathrm{m}^{2} \mathrm{~K}$ was achieved.

Recently, Yoshida and Morigami [11] calculated a interfacial thermal conductance of $2.97 \times 10^{7} \mathrm{~W} / \mathrm{m}^{2} \mathrm{~K}$ for a pure copper $/ 60 \mathrm{vol} . \%$ diamond interface in their composite produced by hot-pressing at about $1180^{\circ} \mathrm{C}$ under an extremely high pressure of $4.5 \mathrm{GPa}$ for $15 \mathrm{~min}$. Obviously, the use of a suitable carbide former results in a better interface design in this material system. However, there is some potential for further improvements, because a thermal conductivity of above $650 \mathrm{~W} / \mathrm{m} \mathrm{K}$ can be estimated for a $42 \%$ diamond containing composite.

The CTE of the $\mathrm{CuCr} /$ diamond composites was not strongly affected by changing the pressing regime and was maintained at about $11 \times 10^{-6} \mathrm{~K}^{-1}\left(30-200^{\circ} \mathrm{C}\right)$. However, the results suppose

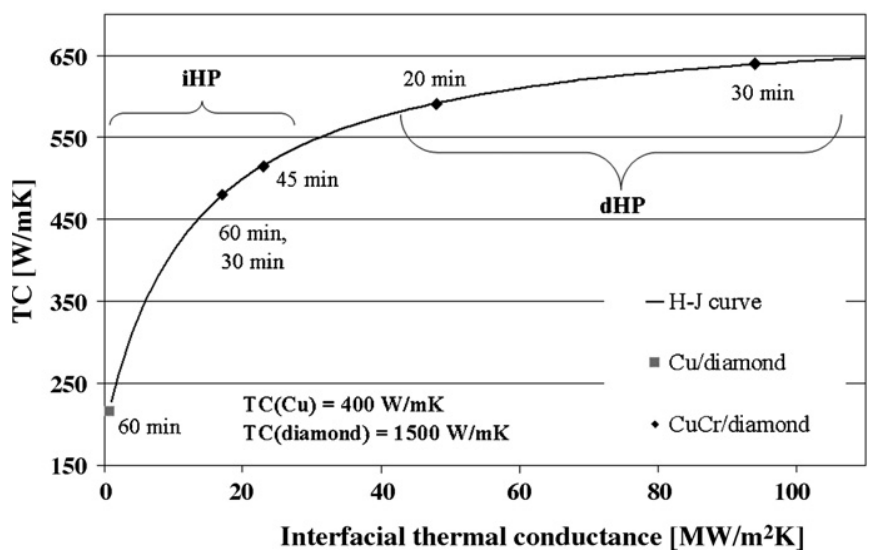

Fig. 6. Thermal conductivity (TC) of $42 \%$ diamond containing composites as a function of the interfacial thermal conductance (iHP: indirectly heated hot pressing; dHP: directly heated hot pressing; H-J curve: Hasselmann/Johnson model). slight lower CTE values (5\% lower) in case of the composites with the higher TC values. This effect has to be confirmed by further measurements.

\section{Conclusion}

Copper based composites containing about 40 vol. $\%$ particle reinforcement (silicon carbide or diamond) were fabricated by hot pressing of powder mixtures. In order to influence the interface design between copper and the reinforcing particles two approaches were investigated.

Composite fabrication is feasible by the proposed method using $\mathrm{SiC}$ powders coated with Mo by sputtering. Obviously, Mo coating effectively controlled the reaction between $\mathrm{SiC}$ and copper. The control of this interfacial reaction is crucial to enable manufacture of $\mathrm{Cu}-\mathrm{SiC}$ heat sinks with high thermal conductivity.

The highest thermal conductivities should be possible with diamond reinforced $\mathrm{CuCr}$ or $\mathrm{CuB}$ matrix composites. The preparation of the most promising $\mathrm{Cu}$ /diamond composite resulted in a thermal conductivity of about $640 \mathrm{~W} / \mathrm{m} \mathrm{K}$ combined with a CTE of about $11 \times 10^{-6} \mathrm{~K}^{-1}\left(\mathrm{RT}-200^{\circ} \mathrm{C}\right)$. Rapid hot pressing is a promising technique for consolidation of $\mathrm{Cu} /$ diamond composites. In addition, the dHP technique is an already well established method for fabrication of diamond cutting tools today.

However, further research activity is needed in order to

(i) optimise the type and thickness of the intermediate reaction layers,

(ii) increase the volume content of the diamond particles to reduce the CTE value,

(iii) optimise the processing parameters (temperature, time, heating/cooling rates).

\section{Acknowledgements}

Dr. Fritsch, Germany is gratefully acknowledged for conducting the fast hot pressing experiments.

This work has been performed within the framework of the Integrated European Project "ExtreMat" (contract NMPCT-2004-500253) with financial support by the European Community. It only reflects the view of the authors and the European Community is not liable for any use of the information contained therein. 


\section{References}

[1] C. Zweben, Adv. Packag. 15 (2) (2006) 1-5.

[2] R.M. German, K.F. Hens, J.L. Johnson, J. Powder Metall. 30 (2) (1994) 205-215.

[3] T. Weißgärber, G. Lefranc, J. Schulz-Harder, H. Meyer, O. Stöcker (Eds.), Advances in Powder Metallurgy \& Particulate Materials, part 6, Metal Powder Industries Federation, Princeton, NJ, 2003, pp. 33-40.

[4] G. Sundberg, Adv. Microelectron. Nov./Dec. (2004) 8-11.
[5] G. Sundberg, P. Paul, Ch. Sung, Th. Vasilos, J. Mater. Sci. 40 (2005) 3383-3393.

[6] Q. Sun, O.T. Inal, Mater. Sci. Res. B 41 (1996) 261-266.

[7] H. Schmidt-Brücken, W. Schlapp, Z. Angew. Phys. 32 (1971) 307-310.

[8] B. Dewar, M. Nicholas, P.M. Scott, J. Mater. Sci. 11 (1976) 1083-1090.

[9] A.E. Martinelli, R.A.L. Drew, Mater. Sci. Eng. A 191 (1995) 239-247.

[10] D.P.H. Hasselmann, L.F. Johnson, J. Compos. Mater. 21 (June) (1987) 508-515.

[11] K. Yoshida, H. Morigami, Microelectron. Reliab. 44 (2004) 303-308. 